\title{
Verbally Conditioning Client Behaviors in the Therapeutic Setting
}

\section{El Condicionamiento Verbal de la Conducta de los Clientes en Contextos Terapéuticos}

\author{
Henry D. Schlinger, Jr. \\ California State University, Los Angeles, USA
}

\author{
Galen Alessi \\ Western Michigan University, USA
}

\begin{abstract}
In this article we address the question of how a client's behavior can be changed by the verbal interactions in the therapeutic setting. We suggest that when such change occurs, regardless of the theoretical orientation of the therapist, the client's behavior has been verbally conditioned. In particular, any verbal stimulus in the therapy setting that produces such change alters the function of settings in which the problem behaviors or feelings normally occur to evoke different, that is, healthier, verbal and nonverbal behaviors or feelings. We point out that such verbal conditioning is ongoing and ubiquitous both in and out of the therapy setting, and that not only are clinically relevant improvements conditioned by a client's self-talk, but so are the very problems the client experiences in the first place. Finally, we present several examples of how the client's behaviors outside the therapy situation may be altered by the verbal interactions with a therapist.

Keywords: clinical behavior analysis, function-altering operations, psychotherapy, verbal conditioning.
\end{abstract}

Resumen. En este artículo se aborda la cuestión de cómo, a través de las interacciones verbales en contextos terapéuticos, se puede cambiar la conducta de un cliente. Sugerimos que, cuando se producen cambios de este tipo, independientemente de la orientación teórica del terapeuta, se ha producido condicionamiento verbal de la conducta del cliente. Concretamente, cualquier estimulo verbal en un contexto terapéutico que provoque tal cambio alterará también la función de contextos donde normalmente se producen las conductas o sentimientos problemáticos. Estos serán substituidos por otros sentimientos o conductas, verbales y non verbales, más sanos. Señalamos que este tipo de condicionamiento verbal tiene que ser continuo y presente siempre, tanto en el contexto de las sesiones terapéuticas como fuera de ellas, y que no solo las mejoras clínicamente relevantes se ven condicionadas por el autodiálogo del cliente, sino que también lo están los mismos problemas que experimenta el cliente. Por último, presentamos varios ejemplos de como las conductas del cliente fuera de la sesión terapéutica pueden sufrir cambios por medio de sus interacciones con el terapeuta.

Palabras clave: análisis clínico de conductas, condicionamiento verbal, operaciones de cambio de funciones, psicoterapia.

The question we address in the present article is: "How can the talking that goes on during the [therapy] session help a client with problems that occur

Correspondence concerning this article should be addressed to Henry D. Schlinger, Jr. Department of Psychology, California State University, Los Angeles. Los Angeles, CA 90032-8227. E-mail: hschlin@calstatela.edu outside the session in the client's daily life" (Kohlenberg, Tsai, \& Dougher, 1993, p. 271)? Or, more technically: How can a client's verbal and/or nonverbal behavior be altered (i.e., brought under the control of new or different motivating operations and discriminative stimuli) as a function of what goes on in the therapeutic setting? 
A complete account of the mechanisms by which a client's behavior is changed in a therapeutic setting must include direct classical conditioning through such intentional techniques such as systematic desensitization or incidentally through higher-order pairing of verbal stimuli, or by operant conditioning as, for example, when therapists reinforce, whether intentionally or inadvertently, verbal behavior by the client. Of course, there are other methods based on operant conditioning in which clients are instructed to arrange behavioral contingencies (contingency management) or cooperate in writing behavioral contracts to help reduce or change unwanted behavior or to encourage desired behavior. But these methods involve straightforward techniques and are therefore excluded from the present account.

The present article will focus on the more subtle process of changing the client's behavior in or out of the therapeutic setting solely as a function of statements by the therapist or the client him- or herself. It is not our intention to render judgment on which, if any, psychotherapeutic interventions result in effective behavioral or emotional changes in clients, but rather to suggest what mechanisms might be involved if such successes do occur.

\section{Background}

Numerous psychotherapeutic techniques have been proffered over the years. Some (e.g., psychoanalysis and Rogerian self-directed therapy) are referred to as insight therapies because there is an inherent assumption that gaining insight into one's problems is either the first, or perhaps the only, step to change. Although the insight therapies claim that insight into one's problems is responsible for behavior change, sometimes when such change takes place evidence points to other variables. For example, Truax (1966) reviewed audiotapes of an extended therapy session by Carl Rogers in an effort to document Rogers' claim that empathy and positive regard were provided unconditionally, that is, noncontingently on the client's behavior. Instead, Truax found that Rogers responded differentially to five of the nine classes of patient behaviors identified and that four of those five increased over the course of the session, demonstrating a positive reinforcement effect.

Other, more recent, psychotherapeutic approaches rely upon getting clients to talk differently about their problems as they perceive them, as happens in different versions of cognitive behavior therapy (CBT), for example the Cognitive Therapy of Aaron Beck (e.g., A. Beck, 1991; J. Beck, 1995), the Rational Emotive Behavior Therapy (REBT) of Albert Ellis (e.g., Ellis, 1988, 2001), or the reframing technique in some forms of Family Systems Therapy (e.g., Watzlawick, Weakland, \& Fisch 1974). These approaches to psychotherapy have several features in common with each other and with a behavior analytic approach to behavior change. First, each deals directly with the client's presenting problem rather than trying to reconstruct the past in the search of underlying causes. As Watzlawick et al. state,

What, it is usually asked, about the undeniable fact that a person's present behavior is the result of his experiences in the past? How can an intervention that leaves past causes untouched have any lasting effect in the present? But it is these very assumptions that are the most clearly contradicted by the study of actual - particularly spontaneous - changes. Everyday, not just clinical experience, shows not only that there can be change without insight, but that very few behavioral or social changes are accompanied, let alone preceded, by insight into the vicissitudes of their genesis. (1974, p. 86).

A second feature common to cognitive psychotherapeutic approaches is an acceptance of the so-called cognitive model. The cognitive model "hypothesizes that people's emotions and behaviors are influenced by their perception of events. It is not a situation in and of itself that determines what people feel but rather the way in which they construe a situation" (J. Beck, 1995, p. 14). By this, cognitive therapists mean that no situation by itself can make someone feel sad, depressed or anxious. Rather, it is how a person thinks about or perceives the situation that determines what he or she feels and how he or she behaves. More than one cognitive theorist (e.g., Ellis, 1988; Watzlawick et al., 1974) has cited quotations by the philosopher Epictetus who said, "It is not the things themselves which trouble us, but the opinions we have about these things," and by 
Shakespeare who said in Hamlet, "There is nothing either good or bad, but thinking makes it so." Of course, by "think" or "perceive," cognitive therapists mean how people talk to themselves; in other words their verbal behavior about a situation. This self-talk is sometimes called automatic thoughts which are said to represent the core beliefs a person holds about him- or herself (J. Beck, 1995). As we suggest later, much of this self-talk alters the function of various features of the situations in which the clients experience their problems such that those features evoke either maladaptive self-talk or other behaviors.

A final feature shared by cognitive approaches to psychotherapy, at least on the surface, is that each entails strictly verbal interactions between a therapist and a client, for example, Socratic questioning and guided discovery of cognitive therapy (e.g., J. Beck, 1995), the reframing method of family systems therapy (e.g., Watzlawick et al., 1974), or changing irrational into rational thinking as prescribed by REBT (Ellis, 1988). The behavior analytic approaches described below also share these features with the cognitive therapies, although the terminology and conceptual framework differ. This, we think, is evidence that all of these approaches to therapy, as verbal repertoires, are themselves under the control of the same variables.

\section{Clinical Behavior Analysis}

Therapists who employ the principles of behavior analysis in their practice are referred to as clinical behavior analysts. Clinical behavior analysis (CBA) is based on the assumption that the client's problems also occur within the therapy session, implying that "the occurrence of problems during the session is evidence for its functional similarity to daily life" (Kohlenberg et al., 1993, p. 274). Thus, CBA takes a two-pronged approach to the problems presented by clients in a therapeutic setting.

The first is "a contemporary strand of officebased talk therapy based on a functional analysis of the client-therapist relationship" (Vandenberghe, 2008, p. 70) called functional analytic psychotherapy (FAP). FAP assumes that because many of the client's problem behaviors are the result of interper- sonal difficulties, such behaviors will be revealed in his or her interaction with a therapist and that those behaviors, referred to as clinically relevant behaviors, can improve in the same setting as a function of that interaction. As Follette \& Bonow (2009) put it,

Because many problems that lead to distress and impaired role function are the result of interpersonal deficits, the therapy environment can be made to have features much like the natural environment ... Change occurs as the therapist helps the client to discriminate opportunities to behave in more adaptive ways and shapes the client's repertoire so that social interactions result in meaningful social reinforcement . . . the therapist establishes him- or herself as an important mediator of interpersonal reinforcement. It is the contingent responding of the therapist to clinical problems and improvements that occur in the therapy session that produces change that will be maintained outside the therapy session (p. 137).

The crux of FAP is essentially for the therapist to use the principles of behavior analysis to strengthen appropriate interpersonal behaviors through the use of social reinforcers the client would hopefully encounter outside the therapy session, and to weaken inappropriate behaviors through social punishment and extinction that resemble the kinds the client might experience in their daily interactions. Thus, the goal of FAP is essentially to attempt to program the therapy session for generalization by incorporating techniques noted by Stokes \& Baer (1977), such as introducing natural contingencies and programming common stimuli. But FAP seems to focus more on direct shaping of social behaviors in session rather than using verbal function-altering operations (FAOs) to alter the evocative effects of various stimuli in the client's problematic settings.

Some clinical behavior analysts take a more indirect approach to changing a client's behavior, and that is through the use of verbal behavior theory and research, primarily through what has been referred to as rule governance, because as Kohlenberg et al. (1993) state, it very likely plays an important role in the etiology of clinical problems and the process by which the verbal behavior that occurs within sessions influences the client's behavior outside the session. (p. 278). 
In fact, as described above with the cognitive therapies, a client's self-talk either creates or compounds a variety of problem behaviors related to depression and anxiety. With depression, for example, the core experience may be "an elicited response to environmental events that produce reductions in positive reinforcement," for example, the death of a loved one or divorce, but that core experience is often exacerbated by how the client talks about it (Kanter et al., 2008, p. 11).

A client's self-talk may itself elicit anxiety as a conditional stimulus. It may also function as a motivation operation by momentarily increasing the reinforcing value of escaping the anxiety or the situation and by evoking (i.e., momentarily increasing the probability of) responses that result in escape or avoidance of anxiety elicited by the self-talk or by certain situations; or it may enhance the control by certain discriminative stimuli (see Wray et al., 2009). Such self-talk is also involved in what has been called cognitive bias, that is, the selective attending, remembering, and attributional biases found in certain clinical populations (Wray et al., 2009). A critical question for the present article is, How do verbal stimuli exert control over behavior (Kohlenberg et al., 1993)? To answer this question, we first describe some different behavioral functions of verbal stimuli.

\section{Basic Behavioral Functions of Verbal Stimuli}

Without entering into the debate over what exactly a verbal stimulus is, suffice it to say that stimuli we most often speak of as verbal function more or less the same way that nonverbal stimuli do, that is as unconditional and conditional stimuli (USs and CSs) in Pavlovian or respondent conditioning, and as discriminative stimuli (SDs and S-deltas), motivating operations (MOs), and reinforcing and punishing stimuli in operant conditioning.

\section{Respondent and Operant Evocative Functions}

Like nonverbal stimuli, verbal stimuli may have respondent evocative functions. For example, screaming an expletive, through no special verbal- ness of the stimulus, can, as a US, evoke a startle response. If a verbal stimulus has been paired either with a US or another CS (as in higher-order conditioning), it may evoke a conditional response (CR). As a result, verbal events (i.e., words or sentences) may evoke a range of CRs that are relevant for therapeutic intervention and that we describe with terms such as anxiety, depression, sadness, fear, and sexual arousal. For example, a woman may say to herself that no one likes her, and such statements may evoke responses that she labels as depression. Or when she goes to the store and sees women she thinks are attractive she may say to herself that she is ugly by comparison, and such statements may evoke feelings she describes as anxiety. Likewise, obsessive thinking (self-talk) in individuals diagnosed with obsessive-compulsive disorder (OCD) elicits anxiety. (Such CS effects occur as a function of mostly unknown histories of pairing with other, both first and second order, events, or due to certain verbal operations, which alter the functions of stimuli that evoke those reactions (see below)).

In addition to respondent evocative functions, verbal events constantly evoke operant behavior relevant to therapeutic settings as $\mathrm{S}^{\mathrm{D}} \mathrm{S}$ and as MOs. In the example described above, if going to the store evokes anxiety (usually in concert with the woman's own self-talk), she might say to herself that she needs to leave or avoid that situation. Or, a person diagnosed with OCD might say she needs to check to make sure that the stove is off or that the door is locked. The statements in concert with the situation elicit anxiety and, as MOs, simultaneously make anxiety reduction more valuable as a (negative) reinforcer, and increase the momentary probability of escape and avoidance. Some self-statements may also seem to function as $\mathrm{S}^{\mathrm{D}}$ s by increasing the momentary probability of the escape or avoidance behavior. (Notice that the statements may not technically be $S^{\mathrm{D}} \mathrm{s}$, that is, they may not have been present in the past when the reinforcement for such behavior was differentially available. In such cases, they would be more appropriately termed analogue $S^{\mathrm{DA}}$ S (Alessi, 1992).) Although we may have correctly identified the functional antecedents (MOs and $\mathrm{S}^{\mathrm{D}} \mathrm{s}$ ) in these instances, we have not identified the processes or conditioning 
history through which they have acquired their evocative properties.

In the present article we are more interested in the effects of verbal stimuli referred to as function altering (e.g., Schlinger \& Blakely, 1987). Function-altering effects have been said to mimic the effects of classical and operant conditioning (e.g., Alessi, 1992; Schlinger \& Blakely, 1994) and it is these effects that may help explain how a client's behavior may be altered both in and out of the therapeutic setting as a result of verbal interactions in the therapeutic setting, including the effects of the client's own verbal behavior on his or her subsequent behavior.

\section{Function-Altering Effects of Verbal Stimuli}

\section{Function-Altering Operations}

Skinner (1953) hinted at the function-altering nature of reinforcement, and of operant conditioning in general, when he wrote the following:

The net result of reinforcement is not simply to strengthen behavior but to strengthen it in a given state of deprivation. Reinforcement thus brings behavior under the control of an appropriate deprivation. After we have conditioned a pigeon to stretch its neck by reinforcing with food, the variable which controls neck-stretching is food deprivation. The response of stretching the neck has merely joined that group of responses which vary with this operation. We can describe the effect of reinforcement in no simpler way. (p. 149)

Thus, reinforcement does not strengthen behavior directly as is so often stated, but rather it brings behavior under the control of MOs and $\mathrm{S}^{\mathrm{D}} \mathrm{s}$. In other words, reinforcement, punishment, and extinction are FAOs, altering (either strengthening or weakening) the evocative functions of MOs and $\mathrm{S}^{\mathrm{D}} \mathrm{s}$. Moreover, all respondent or Pavlovian and operant conditioning operations are function altering in that they alter the evocative functions of antecedent stimulus conditions (Schlinger \& Blakely, 1994). Although it is important to conceptualize the nonverbal operations of operant and respondent conditioning as FAOs, it is perhaps even more important to recognize that verbal events can also be function altering.
As already mentioned, Skinner (1957) called attention to the function-altering aspects of verbal stimuli, although he did not use that term, when he described the effects of relational autoclitics. Subsequently numerous authors have described similar effects of verbal stimuli (e.g., Alessi, 1992; Hayes \& Hayes, 1989; Schlinger \& Blakely, 1987), although only two (Alessi and Schlinger \& Blakely) have used the term "function altering." The term simply describes certain effects of verbal and nonverbal operations; it does not imply any explanatory mechanisms, although elsewhere Schlinger (2008a) offered an interpretation of the genesis of verbal FAOs. As implied previously, verbal FAOs, like their nonverbal counterparts, can either bring behavior under the control of MOs or $\mathrm{S}^{\mathrm{D}} \mathrm{s}$ or alter (i.e., strengthen or weaken) existing control by such antecedent events over behavior.

\section{Verbal Function-Altering Operations}

Recently, Schlinger (2008a) wrote that, "In a brief 10-page section of Verbal Behavior placed, almost as an afterthought, at the end of Chapter 14, titled Conditioning the Behavior of the Listener, Skinner addressed what may be the most interesting feature of verbal behavior" (p. 310). In that section of Verbal Behavior, Skinner (1957) noted that although relational autoclitics may evoke behavior as $\mathrm{S}^{\mathrm{D}} \mathrm{s}$, they have "a different and highly important effect," namely to change the probability of future behavior in a similar manner to operant and respondent conditioning; hence, according to Skinner, relational autoclitics condition the behavior of the listener. Subsequently, Skinner (e.g., 1969, 1989) had numerous opportunities to expand on that suggestion, but instead became sidetracked with his analysis of rules and rule-governed behavior (Schlinger, 2008a).

When Skinner first described rule-governed behavior and distinguished it from contingencyshaped behavior, he interpreted the rule statement as

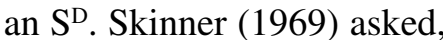

How does a rule govern behavior? As a discriminative stimulus, a rule is effective as part of a set of contingencies of reinforcement. A com- 
plete specification must include the reinforcement which has shaped the topography of a response and brought it under the control of the stimulus. (p. 148).

However, $\mathrm{S}^{\mathrm{D}} \mathrm{s}$ evoke behavior because in the past reinforcement for the behavior has been differentially available in the presence of such stimuli, and this is a different effect than the one Skinner introduced, but never returned to, in that brief section of Verbal Behavior. Much later, others (e.g., Schlinger \& Blakely, 1987, Blakely \& Schlinger, 1987, Schlinger, 1993, Schlinger \& Blakely, 1994) described similar phenomena they referred to as function-altering effects of verbal stimuli and argued that they were analogous to effects produced by operant and respondent conditioning (see also Alessi, 1992). These authors distinguished functionaltering effects from discriminative (and motivational) effects. Specifically, events are function altering when, like direct conditioning, they bring behavior under the control of $\mathrm{S}^{\mathrm{D}} \mathrm{S}$ or MOs or when they convert neutral stimuli into CSs, or, indeed, when they alter operant or respondent stimulus control in any way. In fact, Skinner (1957) provided numerous examples of verbal FAOs in his discussion of instruction in Verbal Behavior. For example,

The verbal stimulus "When I say 'three,' go!" may have no immediate effect classifiable as a response, but it changes the subsequent behavior of the listener with respect to the stimulus "Three." We are... concerned... with the operant behavior of "going" evoked by the discriminative stimulus "three." (pp. 358-359).

As Schlinger (2008a) previously noted, "The statement "When I say 'three,' go!" conditions the behavior of going to the stimulus "three," much like a direct reinforcement history would" (p. 314), but only in an appropriate context (e.g., a race). Additionally, Schlinger suggested that we may not want to call the stimulus "three" an $\mathrm{S}^{\mathrm{D}}$ because its natural history of conditioning is unclear. Therefore, we may want to call it an analogue $\mathrm{S}^{\mathrm{D}}$ (Alessi, 1992). Likewise, Skinner (1957) offered the following example of respondent instruction: "When you hear a bell, you will feel a shock," implying that, as a function of hearing this statement, the previously neutral sound of the bell would be altered such that it now evokes similar sympathetic autonomic nervous system reactions as the shock.

Initially Schlinger (Schlinger \& Blakely, 1987, Blakely \& Schlinger, 1987) described functionaltering verbal stimuli as contingency-specifying stimuli (CSSs), following Skinner's (1969) use of the term when discussing rule-governed behavior. However, more recently, Schlinger (1993, 2008a, 2008 b) noted that a verbal stimulus does not have to be a formal CSS in order to alter the functions of other events (see also Palmer, 2007). As Palmer (2007) stated, "almost any salient verbalization" can condition the listener's behavior. Of course, a "salient" stimulus is simply one which can bring about such conditioning, or "instruction," as Skinner (1957) called it. So, for example, if we say "Abraham Lincoln," it is very likely that many hours or even days later a listener could report that we said Lincoln's name. Elsewhere, Palmer (1998) has suggested that even a single instance of an intraverbal frame can have function-altering effects. So, if we say, "Lincoln was the $16^{\text {th }}$ president of the United States," later a listener should be able to say "Lincoln" to the question, "who was the 16th president of the United States?" Such evidence suggests that the listener was indeed listening (see Schlinger, 2008b). Schlinger (2008a) speculated how such "conditioning" might occur. However, even in the absence of understanding how FAOs produce their effects, it is important to identify and describe them.

Verbal FAOs have implications for a variety of phenomena related to language, including the main point of the present article, namely, how the verbal behavior of a therapist or of the client him- or herself can alter the behavioral functions of stimuli both inside and outside of the therapeutic setting. In the next section, we describe several examples of how verbal FAOs alter the evocative functions of stimuli outside the therapeutic setting in the client's own problematic environments.

\section{The Role of Function-Altering Verbal Stimuli in Therapy}

Because behavioral relations are constantly being conditioned by verbal FAOs, it is very likely that a 
client's verbal behavior about specific situations alters behavioral functions in ways that perpetuate or exacerbate the client's problems. Consider social fears or phobias. First, it is possible that some aspect of a situation functions as a CS to elicit anxiety as a result of a history of direct conditioning, or, perhaps as a result of higher-order conditioning, a client's self-talk also elicits anxiety. For present purposes, it is also likely that other things the client says to himor herself are function altering. For example, a college student with a fear of public speaking might say something like, "If there is a presentation required in this class, I will die and will have to drop the class." Thus, when on the first day of class the instructor announces that all students have to give a presentation, this student says to himself, "Oh my god, I can't do this," experiences a wave of anxiety, and immediately says to himself, "I have to drop this class." Obviously, there is nothing inherent in the specific situation - the announcement by the instructor - that evokes anxiety or anxiety reducing behavior. It is the student's previous statements about speaking in public that have altered the function of the instructor's announcement to evoke anxiety and additional statements by the student about what he will do.

Alternatively, if dropping the class is not an option, the student might say, "When I have to give my presentation, I can't show the other students that I am anxious." This statement, in the form of a relational autoclitic (Skinner, 1957), may have the effect of exacerbating an already anxiety-eliciting situation because, when the actual presentation occurs, his saying to himself that he cannot let on that he is nervous increases his anxiety. The point is that a client is constantly talking to himself about situations, his feelings, and behaviors in ways that condition relations between all three.

Within the therapeutic setting itself, there are at least two possible opportunities for verbal FAOs to condition relations involving a client's verbal or nonverbal behavior. The first is when the therapist explicitly instructs the client in some manner. Explicit instruction is a major part of cognitive therapy, in particular to identify so-called automatic thoughts, that is, "the actual words or images that go through a person's mind" which "are situation specific . . ." (J. Beck, 1995, p. 16). For example, a therapist might instruct a client "to stop and ask yourself "What is going through your mind' when you notice your mood changing or getting worse" J. (Beck, p. 92). If as a result of this explicit instruction, when such a situation arises $\left(\mathrm{S}^{\mathrm{DA}}\right)$ the client asks herself this question or even reminds herself to ask the question, then the initial instruction has altered the function of the situation or mood to evoke the question. Or, said another way, the therapist's instruction has conditioned the behavior of the client as listener. As Schlinger (2008b) has suggested elsewhere, the client must have listened to the therapist for such conditioning to occur. In other words, the therapist's instruction must have evoked echoic or intraverbal behavior on the part of the client. Thus, it is not the therapist's statement per se which has conditioned the future behavior of the client, but the client's own verbal behavior.

A second way in which verbal FAOs might work in the therapeutic setting is when the therapist's verbal behavior is incidentally function altering. For example, suppose that a REBT therapist explains the ABCs of REBT to a client as follows. The A is the activating event or something that happens to block some goal, for example, a man asks a woman out on a date and she turns him down. The consequence, or $\mathrm{C}$, is that the man feels terrible (e.g., angry, depressed, etc.) and may engage in some self-defeating behaviors (e.g., withdrawal). The Bs are the beliefs (i.e., self-talk), both rational and irrational, that a person has about the activating events that are the real culprits causing the consequences. The man in this example might say that the woman is too good for him and that such a beautiful woman would not want to go out with him anyway, so why try anymore. In any case, if, after explaining the ABCs of REBT, a client finds that a particular situation evokes a restatement of any or all of them, then the client's behavior has been conditioned such that a situation that normally would not evoke verbal behavior about the ABCs of REBT now does. Again, it is not the therapist's statement itself that has produced the conditioning, but rather the client's own echoic and intraverbal behavior evoked by the therapist's explanation.

Of course the client's verbal behavior can and often does condition his or her subsequent behavior. This can happen at any time during the therapeutic 
session, just as it can and does outside the session. The issue for the present article is whether and how it does so that results in clinically relevant changes in behavior.

\section{Some Examples of FAOs in Therapy}

As noted previously, in many different versions of cognitive-based therapies as well as verbally based behavior analytic therapies, the verbal interactions between a therapist and client often result in changes in the client's behaviors outside the therapy setting. We are arguing that, regardless of the specific form of therapy, any changes that do not result from direct classical or operant conditioning in the therapist's office result from function-altering verbal events.

The solutions to clients' problems are often relatively simple, but the reasons clients do not implement those solutions are relatively complex. Focusing on the many FAOs in therapy can increase the chances that clients can successfully implement the main treatment plan. The examples below specifically aim to alter the functions of various (MO-S $-\mathrm{R}-\mathrm{C}$ ) contingencies suspected to be active in the client's daily life. The behavior therapist assesses the client's presenting problem within a behavior analytic framework, and plans rule-based or instruction-following interventions based on analyses of suspected contingencies of reinforcement operating in the client's problem setting. The therapist also anticipates various stimuli that potentially may become activated in the problem settings (in situ) when the plan is implemented at a future time and place, carefully crafting verbal interventions to alter the functions of those "therapy- interfering" stimuli and behavior. The judicious use of these kinds of FAOs may make the difference in whether the plan will be effective.

Altering the evocative effects of pain stimuli with verbal FAOs. The effects on behavior related to pain stimuli can be altered by verbal FAOs. Randomized controlled studies have demonstrated that Tylenol with codeine has a significantly larger effect on pain behavior than simple Tylenol. But studies also demonstrate that simple Tylenol, when the patient is told that it is Tylenol with codeine, is significantly more effective than simple Tylenol, and roughly equal in effect to Tylenol with codeine (Kirsch, 1990). Somehow, the verbal FAO "this Tylenol contains codeine" reduces the evocative effect of future pain stimuli in situ, ameliorating their effects to levels observed when using codeine. Although some call this a "placebo effect," this term is roughly equivalent to: "there is a change, but I don't know how it happened."

Altering the evocative effects of usual setbacks in the therapy process. Therapeutic change does not occur in a steady, smooth manner. On some days the plan will work beyond the client's expectations, but on other days may seem to be ineffective. The client is at risk of stopping the plan on a particularly bad day, thus undermining the entire, carefully designed therapy plan, as well as eroding confidence in the ability of the therapist. The therapist then must backtrack and spend extra time to repair the situation at the next therapy session. The original plan may even have to be abandoned and a new one developed. Therapists who understand how change works would deliver a verbal FAO early in the therapy process to inoculate clients against giving up their plan or hope when they have a bad day (or week). The therapist might say: "From experience we know that change does not occur in a smooth, steady manner. Sometimes there are three steps forward and one step backward. Or it will be five steps forward and four steps backward." Setbacks thus are framed as normal and to be expected: some will be small, while others could be much larger. This verbal FAO may alter the evocative effects of the plan not working in future situations from one of "the plan is not working and something must be wrong and I should stop the plan until the next therapy session," to one of "this is one of those setbacks predicted by the therapist, which actually confirms that she knows what she is doing, and so I should continue the plan and talk to her about her prediction at the next session." In addition to more general FAOs stated by the therapist to inoculate the client against setbacks, the therapist also provides more specific examples of situations or events that may precipitate a bad day or a setback, thus expanding the range of situations altered by the verbal FAO. 
Altering the evocative effects of child attempts to convince parents not to continue therapy. Adolescents rarely look forward to therapy sessions. While her parents may report a list of recent serious transgressions by the adolescent, when asked what she thinks is the problem, she may reply: "I don't have any problem, except getting my parents off my back. They have the problems, work with them." The family may have already tried several therapies, which have failed because the adolescent has managed to sabotage each one. When adolescents refuse to participate and openly defy parents in session, therapists might suspect that the adolescent will try to convince (or browbeat) the parents to discontinue therapy. The adolescent may argue after the session: "Therapy is a waste of time," or "I can't relate to this therapist," or "He is crazy himself." Such resistance is more likely when parents have agreed to implement a realistic therapy plan to improve the adolescent's behavior.

Anticipating these therapy-interfering arguing behaviors, the therapist may say, after the parents have agreed to the plan: "I need to tell you something here. You have already tried many things and they have not worked. So I cannot assure you that this plan will work. But there is one thing we have learned in working with adolescents over the years. If our plan is going to work, your daughter will start to complain about this therapy, or therapist, or approach. She may begin her complaints before you even get to your car. She will certainly increase her complaints when you actually begin to implement the plan. This indicates that this particular therapy likely will be effective. If she does not complain, or is not that concerned, that may indicate that this plan may not work. Watch for her reactions so that you can let me know next week whether we are on the right track here." This verbal FAO alters the evocative effect of the adolescent's arguing (in situ) not to continue therapy from one that shakes the parents' confidence that they are on the right track to one that confirms that they are on the right track. The more the adolescent argues about coming to therapy, the more the parents are convinced that therapy will work. If she doesn't argue, they will return to therapy (not having to fight her) to update the therapist on the plan and progress.
Verbal FAOs that ensure client success in carrying out treatment plans. Therapists plan carefully to ensure that clients are successful in implementing treatment plans. Plans are broken down into the right-sized steps for the particular client. Plans are built on the client's strengths, while avoiding their weaknesses. Plans are designed to be congruent with the client's personal values and beliefs. The bestlaid plans, however, may encounter unanticipated obstacles when being implemented in the client's problematic situation. When plans run into unanticipated therapy-interfering obstacles in situ, the client may become discouraged and lose hope in the plan, if not the therapy. One way to avoid such unanticipated obstacles would be to wrap the plan within a verbal FAO of "assessment." The therapist asks the client to gather more assessment data in order to develop a final treatment plan. The assessment plan includes trying out tentative interventions to see how they work. The client takes notes on what was done, how effective it was, and what obstacles got in the way of implementation. At the next session, therapist and client will go over the assessment data to determine how to proceed. Within this assessment verbal FAO frame, the client cannot fail. If the suggested interventions work, that is success. If certain interventions don't work, the client has successfully determined that this kind of intervention should be avoided, and/or has detected obstacles (in situ) that blocked it from working. A series of successful (by definition) assessment assignments lead step-bystep to successful design and implementation of treatment plans (a kind of errorless therapy).

\section{Summary and Conclusions}

In this article we have suggested that numerous behavioral problems, often accompanied by feelings labeled as anxiety or depression, may be conditioned by the person's own verbal behavior (i.e., self-talk) as FAOs. Such verbal FAOs function in a manner similar to the nonverbal FAOs of operant and respondent conditioning. In other words, what a person says to him- or herself can condition feelings of anxiety or depression and their accompanying behaviors that probably cannot be evoked directly 
by the actual situations themselves. Although not stated in such terms, many versions of CBT share the assumption that situations in and of themselves cannot make someone anxious or depressed or behave in a certain way and that what a person believes (i.e., says) about those situations causes those emotions and behaviors. In addition, we have suggested that what is said in a therapeutic setting, either intentionally or incidentally by the therapist and repeated or restated by a client him- or herself, can and often does alter the functions of other events outside the therapeutic setting.

Having made these two points, we must underscore that our own verbal and nonverbal behavior is constantly being conditioned and that the verbal conditioning that occurs in the therapy setting is not fundamentally any different. The issue is whether such conditioning can bring about clinically relevant improvement in the clients' behaviors and, thus, amelioration of their problems which, according to most modern approaches to therapy, result from how clients perceive, that is, talk to themselves about those situations in the first place. This article suggests that therapists should be more aware of verbal FAOs and should then employ them not only to alter the evocative effects of stimuli in the client's problematic situations but also to counteract the effects of therapy-interfering stimuli in those settings when the therapeutic plan is implemented.

\section{References}

Alessi, G. (1992). Models of proximate and ultimate causation in psychology. American Psychologist, 47, 1359-1370.

Beck, A. T. (1991). Cognitive therapy: A 30- year retrospective. American Psychologist, 46, 368375.

Beck, J. S. (1995). Cognitive therapy: Basics and beyond. New York, NY: The Guilford Press.

Blakely, E. \& Schlinger, H. (1987). Rules: Functionaltering contingency-specifying stimuli. The Behavior Analyst, 10, 183-187.

Ellis, A. (1988). How to stubbornly refuse to make yourself miserable about anything - yes anything! New York, NY: Citadel Press.
Ellis, A. (2001). New directions for rational emotive behavior therapy: Overcoming destructive beliefs, feelings, and behaviors. Amherst, NY: Prometheus Books.

Follette, W. C. \& Bonow, J. T. (2009). The challenge of understanding process in clinical behavior analysis: The case of functional analytic psychotherapy. The Behavior Analyst, 32, 135148.

Hayes, S. C. \& Hayes, L. J. (1989). The verbal action of the listener as a basis for rule-governance. In S. C. Hayes (Ed.), Rule-governed behavior: Cognition, contingencies, and instructional control (pp. 153-190). Reno, NV: Context Press.

Kanter, J. W., Busch, A. M., Weeks, C. E., \& Landes, S. J. (2008). The nature of clinical depression: Symptoms, syndromes, and behavior analysis. The Behavior Analyst, 31, 1-21.

Kirsch, I. (1990) Changing expectations: A key to effective psychotherapy. Pacific Grove, CA: Brooks-Cole Pubs.

Kohlenberg, R. J., Tsai, M., \& Dougher, M. J. (1993). The dimensions of behavior analysis. The Behavior Analyst, 16, 271-282.

Palmer, D. C. (1998). The speaker as listener: The interpretation of structural regularities in verbal behavior. The Analysis of Verbal Behavior, 15, 3-16.

Palmer, D. C. (2007). Verbal behavior: What is the function of structure? European Journal of Behavior Analysis, 8, 161-175.

Schlinger, H. D. (1993). Separating discriminative and function-altering effects of verbal stimuli. The Behavior Analyst, 16, 9-23.

Schlinger, H. D. (2008a). Conditioning the behavior of the listener. International Journal of Psychology and Psychological Therapy, 8, 309-322.

Schlinger, H. D. (2008b). Listening is behaving verbally. The Behavior Analyst, 31, 145-161.

Schlinger, H. \& Blakely, E. (1987). Function-altering effects of contingency-specifying stimuli. The Behavior Analyst, 10, 41-45.

Schlinger, H. D. \& Blakely, E. (1994). A descriptive taxonomy of environmental events and its implications for behavior analysis. The Behavior Analyst, 17, 43-57.

Skinner, B. F. (1953). Science and human behavior. New York: Macmillan. 
Skinner, B. F. (1957). Verbal behavior. New York: Appleton-Century-Crofts.

Skinner, B. F. (1969). Contingencies of reinforcement: A theoretical analysis. New York: Appleton-Century-Crofts.

Skinner, B. F. (1989). The behavior of the listener. In S. C. Hayes (Ed.), Rule-governed behavior: Cognition, contingencies, and instructional control (pp. 85-96). Reno, NV: Context Press. New York: Falmer.

Stokes, T. F. \& Baer, D. M. (1977). An implicit technology of generalization. Journal of Applied Behavior Analysis, 10. 349-367.

Truax, C. B. (1966). Reinforcement and nonreinforcment in Rogerian psychotherapy. Journal of Abnormal Psychology, 71, 1-9.
Vandenberghe, L. (2008). Culture-sensitive functional analytic psychotherapy. The Behavior Analyst, 31, 67-79.

Watzlawick, P., Weakland, J. H., \& Fisch, R. (1974). Change: Principles of problem formation and problem resolution. New York, NY: Norton.

Wray, A. M., Freund, R. A., \& Dougher, M. J. (2009). A behavior-analytic account of cognitive bias in clinical populations. The Behavior Analyst, $32,29-49$.

\section{Authors Note}

The authors are grateful to Michael Dougher and Julie Riggott for their helpful comments and suggestions.

Artículo recibido: 13/06/2011

Revisión recibida: 20/07/2011

Aceptado: 14/09/2011 